\title{
Characteristics of Aerobic Exercise as Determinants of Blood Pressure Control in Hypertensive Patients: A Systematic Review and Meta-Analysis
}

\author{
Lee, Sun Hee ${ }^{1 \oplus} \cdot$ Chae, Young Ran ${ }^{2 \oplus}$ \\ ${ }^{1}$ Department of Nursing, Saekyung University, Yeongwol \\ ${ }^{2}$ College of Nursing, Kangwon National University, Chuncheon, Korea
}

\begin{abstract}
Purpose: The purpose of this study was to evaluate the effect on blood pressure (BP) and heart rate (HR) according to aerobic exercise characteristics in adults with hypertension using a systematic review and meta-analysis. Methods: The related researches were selected from PubMed, EMBASE, Cochrane library, CINAHL, PsycINFO, SPORTDiscus and 5 domestic databases up to September 4, 2019. To estimate the effect size, random effect models were used to derive weighted mean differences (WMD) and their 95\% confidence intervals (CI) of aerobic exercise on BP and HR. Results: A total of 37 RCTs with 1,813 samples were included. Aerobic exercise was found to significantly reduce systolic $\mathrm{BP}(\mathrm{WMD},-8.29 \mathrm{mmHg} ; 95 \% \mathrm{Cl},-10.12$ to -6.46$)$, diastolic $\mathrm{BP}(\mathrm{WMD},-5.19 \mathrm{mmHg} ; 95 \% \mathrm{Cl},-6.24$ to -4.14$)$ and $\mathrm{HR}$ (WMD, - 4.22 beats $/ \mathrm{min} ; 95 \% \mathrm{Cl},-5.36$ to -3.09$)$. In detail, systolic BP and diastolic BP were significantly decreased in all groups of exercise types, frequency and duration. Systolic BP and diastolic BP were significantly decreased in the moderate and vigorous-intensity group. Exercise characteristics with the most dramatical change in systolic BP were water-based training, moderate-intensity, 3 times a week and 8 to 11 weeks of duration. In cliastolic BP, the greatest effect size was over 24 weeks of exercise. Conclusion: Moderate aerobic exercise, especially water-based exercise can be an important part of lifestyle modification for hypertensive patients. Also, it can be recommended in a variety of clinical settings for lowering BP and HR. However, there is insufficient evidence that low-intensity exercise is effective in lowering $B P$.
\end{abstract}

Key words: Hypertension; Exercise; Blood Pressure; Heart Rate; Meta-Analysis

\section{INTRODUCTION}

Hypertension is one of the most common diseases worldwide. A prevalence of hypertension is around $30.0 \sim 45.0 \%$ of adults, rapidly increasing with aging [1]. Also in Korea, the prevalence of hypertension in people over 30 years was $28.3 \%$ and the prevalence in the elderly was $64.3 \%$ [2]. Essential hypertension that accounts for $95 \%$ of all hypertension cases has no identifiable cause, and is considered a primary risk factor that provokes var- ious kinds of complications including cardio-cerebrovascular disease, peripheral vascular disease and/or renal disease [3,4]. Although hypertension is required to be managed actively as a typical chronic disease that is a primary risk factor of cardiovascular disease, stroke, etc. [5], blood pressure (BP) control rate of hypertensive patients was as low as $45.4 \%$ [2]. It is generally known that lowering $10 \mathrm{mmHg}$ in systolic BP may reduce 20.0\% cases of cardiovascular disease, $17 \%$ of coronary artery disease, $27.0 \%$ of stroke, $28.0 \%$ of heart failure, and $13.0 \%$ of the total

\footnotetext{
* This manuscript is a revision of the first author's doctoral dissertation from Kangwon National University. Year of 2020.

Address reprint requests to: Chae, Young Ran

College of Nursing, Kangwon National University, 1 Gangwondaehak-gil, Chuncheon 24341, Korea

Tel: +82-33-250-8880 Fax: +82-33-259-5636 E-mail: yrchae@kangwon. ac. kr

Received: July 23, 2020 Revised: September 21, 2020 Accepted: October 27, 2020 Published online December 31, 2020

This is an Open Access article distributed under the terms of the Creative Commons Attribution NoDerivs License. (http://creativecommons. org/licenses/by-nd/4. 0)

If the original work is properly cited and retained without any modification or reproduction, it can be used and re-distributed in any format and medium.
} 
mortality rate [6], and therefore blood pressure control of hypertensive patients plays a vital role to prevent heart disease or cerebrovascular disease.

Once diagnosed with hypertension, lifestyle modification is encouraged to begin first as a nonpharmacological treatment prior to pharmacotherapy [7]. Among the nonpharmacological treatment methods, regular physical activity has been emphasized, and regular aerobic exercise is accordingly been encouraged [7,8]. Any sport or activity that works large groups of muscles, is continually maintained and performed rhythmically, is defined as an aerobic, or cardiovascular, exercise by the American College of Sports Medicine (ACSM). Aerobic exercise reduces risk of cardiovascular disease as well as controlling BP, and therefore is now actively recommended especially in the European and US hypertension guidelines [5,9].

Increased heart rate (HR) has been associated with high blood pressure and risk factors for accidental cardiovascular disease because it is associated with an imbalance in the autonomic nervous system that can affect blood pressure [10,11].

For such reasons, many studies of effects of aerobic exercise on $\mathrm{BP}$ and $\mathrm{HR}$ of hypertensive patients have been performed, but results of its characteristics and effectiveness varied depending on each study [A1-A37]. Types of aerobic exercise recommended to hypertensive patients include walking, running, bike-riding, aerobic dance, dance, swimming, etc. [3]. Among these, a number of studies including walking and running were conducted [A1-A3], while studies applying water-based training including swimming and aquarobic [A4,A5] and other various types of aerobic exercise including bike-riding [A6,A7] and dance [A8,A9] have also been conducted. Effects of moderate-intensity exercise have been reported in a greater number of studies of aerobic exercise for hypertensive patients [A3,A5,A10,A11], while some studies introduced effects of vigorous-intensity [A7,A12] and low-intensity [A13,A14] aerobic exercise. Frequency of aerobic exercise provided to hypertensive patients widely ranged from two to five days weekly and durations spanned between 4 weeks and 37 weeks [12]. Still, optimal exercise programs structured for hypertensive patients have not been clearly established [13]. Thus, it is necessary to examine the effects of aerobic exercise provided to hypertensive patients and determine the most effective exercise program for reducing $\mathrm{BP}$.
There have been several systematic reviews with meta-analysis of studies that examined effects of aerobic exercise on hypertensive patients [14-17]. These studies included only some of types of aerobic exercise [14,15] or other interventions such as diet with aerobic exercise [14]. One paper [15] included non-randomized controlled trials (RCTs) studies. Also most of these studies $[14,15,17]$ have not been analyzed according to the characteristics of exercise. In only one study [16], the effect on BP was analyzed according to exercise characteristics, but not only patients with hypertension but also normotensive persons and other interventions other than aerobic exercise were included. Another recently published study [17] reported that the number of papers was small and the heterogeneity was high, and also additional study with larger sample sizes to compare exercise characteristics should be considered.

Thus, the aims of this study were to (1) identify effects of aerobic exercise on hypertensive patients, and, further, to (2) compute effect sizes that would impact on systolic and diastolic BP by exercise characteristics such as types, intensity, frequency and duration, and (3) verify its effects on heart rate, by systematically reviewing and conducting meta-analysis for studies with RCTs.

\section{METHODS}

\section{Inclusion criteria}

This study has been performed according to Preferred Reporting Items for Systematic review and Meta-Analyses (PRISMA) guidelines [18]. Key questions for studies selection were formed using PICOT-SD (participant, intervention, comparison, outcome, time and study design) framework, and the details are as follows: 1) participants were adults aged 18 years and older who were diagnosed with hypertension. There was no limited on the use of antihypertensive drugs; 2) intervention was only performed regularly aerobic exercise; 3) comparison was performed with control group did not receive any aerobic exercise; 4) primary outcome of aerobic exercise was systolic and diastolic BP, while secondary outcome was heart rate; 5) Time was not limited. All of the articles published on September 4th, 2019 or earlier were included in literature search. 6) for study design, randomized controlled trials were included. Only studies published in journals 
were included. The exclusion criteria were as follow: 1) studies using other than special intervention, such as resistance exercise, an improved diet or a change in lifestyle; 2) studies without using an experimental design (e.g., surveys, qualitative studies, etc.) or ones with single-group experimental.

\section{Search strategies}

Before collecting data for this study, exemption approval of deliberation was granted by Research Ethics Committee of Kangwon National University (KWNUIRB-2019-07-006). The search was restricted to the Korean or English literature. International database search engines included PubMed, EMBASE, Cochrane library, CINAHL, PsycINFO, and SPORTDiscus, while domestic search engines included Korean Medical Database (KMBase), Korea Institute of Science and Technology Information (KISTI), Korean Studies Information Service System (KISS), National Digital Science Library (NDSL), and Research Information Sharing Service (RISS).

For the international search engines, search terms were chosen using MeSH terms and Entree. The Search terms were (hypertension OR high blood pressure) AND (physical activity OR physical fitness OR jogging OR walking OR swimming OR swim OR aquatic exercise OR aquarobic OR aquatic training OR dancing OR dance OR aerobic dance* OR bicycling OR cycling).

A pair of our researchers proceeded with search in each of the search engines after discussions, and one of them eliminated duplicated articles using a document management program. Based on the selection criteria, then, titles and abstracts were reviewed followed by selection of the studies. Disagreements were solved by communication between the authors.

\section{Data extraction}

Data extraction table has been created for data coding of literature selected. Items of the data coding included article information (author and publication year), subjects (participants, total number of participants, number of exercise groups, number of controlled groups, age, gender, and country where study was conducted), exercise intervention (types of exercise, exercise intensity, frequency, and duration), and study results. Exercise intensity is classified into low-intensity, moderate-intensity, and vigorous-intensity based on Park's et al. [19]. Duration was in- cluded at least 4 weeks or longer to investigate the effect of aerobic exercise based on previous studies [13,20]. When the results of several periods were presented in the same study, each case was analyzed separately. Data were extracted by a pair of researchers followed by double-check comparison with the original data by the other one.

\section{Risk of bias in individual studies}

Two researchers independently assessed the risk of bias of the selected studies using the risk-of-bias tool 2 (RoB2) provided by Cochrane Collaboration [21]. Since the researchers have been conducted several systematic reviews, we could easily agree through discussions in case of inconsistent risk of bias assessment. The RoB2 consisted of five domains of bias to assess, i.e. randomization process, deviation from the intended interventions, missing outcome data, measurement of the outcome, and selection of the reported results. Each of the 22 questions in total was marked as "yes", "probably yes", "probably no", "no", or "no information" and divided into three groups of low risk, some concerns and high risk.

\section{Meta-analytical and statistical methods}

The characteristics of the literature selected for the systematic review were summarized in a table, and meta-analysis was implemented using meta-analysis packages in R program ( $\mathrm{R}$ Foundation for Statistical Computing, Vienna, Austria). The mean effect size was calculated by using a random effects model assuming due to differences of participant characteristics, interventions, etc. in each study.

The Weight Mean Difference (WMD) was calculated for the systolic and diastolic BP and heart rate in consideration that the scale for each outcome variable is a continuous variable $(\mathrm{mmHg}$ for the systolic and diastolic $\mathrm{BP}$; beats/min for the heart rate). Using differences between post and pre-mean values and standard deviation, analysis of the effect sizes was conducted. Along with overall effect sizes, effect size of BP was analyzed by exercise types, intensity, frequency and duration. Statistical significance of effect size was determined with $95 \%$ confidence interval (CI). The negative value of the effect size means that BP and HR have decreased.

To assess the heterogeneity of the effect size, Higgins' $I^{2}-$ 
value were used. In general, when the $I^{2}>75 \%$ was interpreted as high heterogeneity, $25 \%<I^{2} \leq 75 \%$ as moderate heterogeneity, and $I^{2}<25 \%$ as low heterogeneity [22]. To explore major causes of heterogeneity, meta-analysis with ANOVA or regression was carried out.

To examine publication bias, furthermore, funnel plots were used for visualization and then Egger's regression test was performed for statistical verification.

\section{RESULTS}

\section{Study selection}

A total of 9,723 articles were retrieved from the international database search engines and 570 articles from the domestic engines. After excluding duplicate, 6,544 studies remained and 148 were identified based on the title and abstract review. After reviewing the 148 articles, we excluded 111 articles for following reasons: 14 articles did not involve a hypertensive population, 10 articles were inappropriate comparison, 42 articles were study design was unconformable to the criteria, 4 articles included an additional intervention, 6 articles did not published was not in Korean or English, 14 articles were not published in the journal such as letter or thesis, 3 articles could not find the full text, 14 articles did not report statistical result and 4 articles reported duplicate of the same study (Figure 1). Finally 37 articles were selected and listed in the Appendix 1.

\section{Characteristics of selected studies}

The characteristics of the 37 included studies are shown in Table 1. Of the 37 articles, five were published earlier than 2000 (13.5\%), seven in between 2000 and 2010 (18.9\%), and twenty-five in 2011 or later (67.6\%). Countries the studies were conducted were Korea (7 articles), USA (7 articles), Germany (3 articles), Brazil (4 articles), Denmark (2 articles), Iran (2 articles), Nigeria (2 article), Japan (2 article), China (2 article), Britain (1 article), Switzerland (1 article), Malaysia (1 article), Nor-

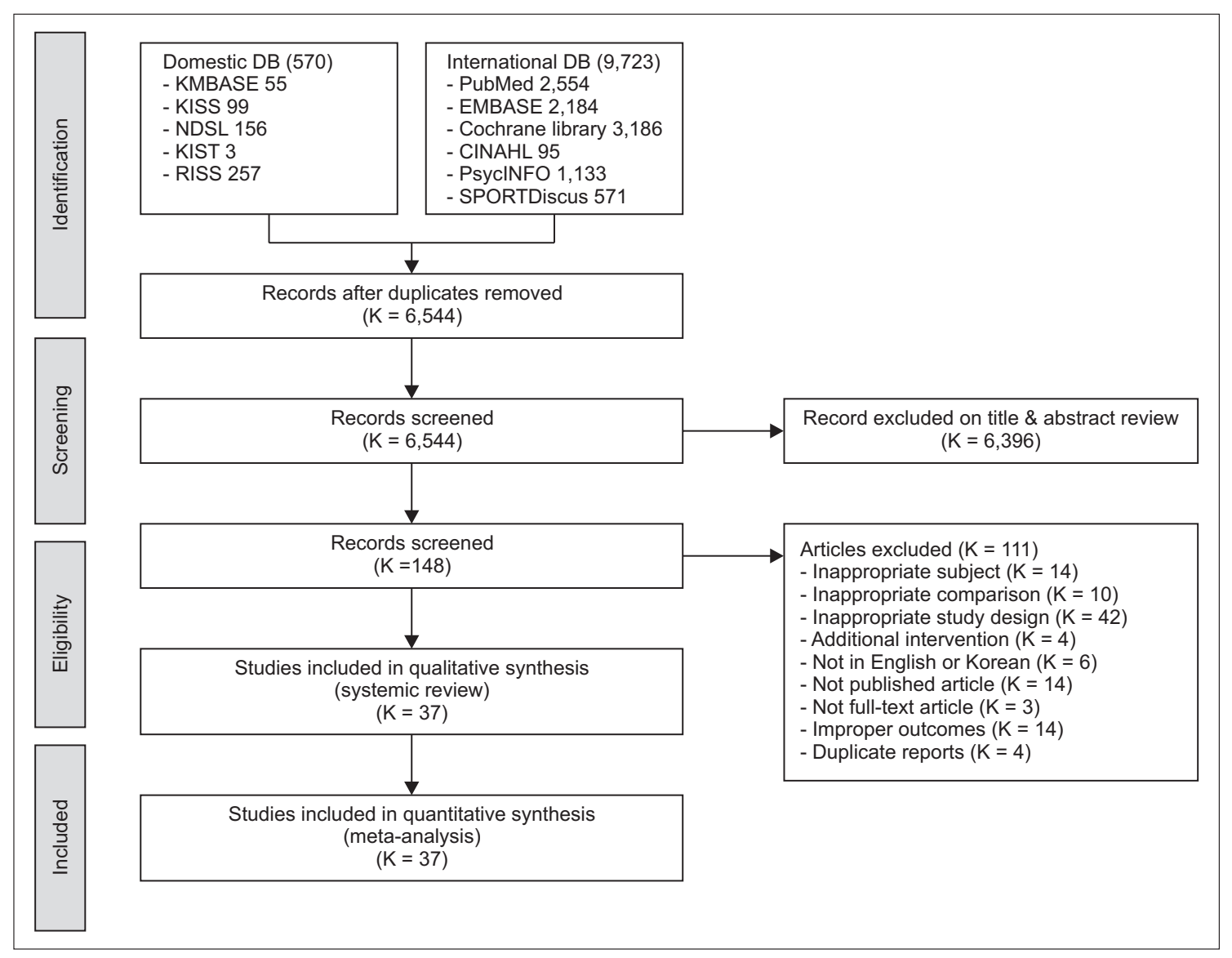

Figure 1. Flow diagram of the study selection process. 
Table 1. Summary of Randomized Controlled Trials Examining Aerobic Exercise

\begin{tabular}{|c|c|c|c|c|c|c|c|c|c|c|c|c|}
\hline \multirow{2}{*}{ No } & \multirow{2}{*}{ First author (yr) } & \multirow{2}{*}{ Country } & \multicolumn{2}{|c|}{$\begin{array}{l}\text { Sample } \\
\text { size }(n)\end{array}$} & \multirow{2}{*}{-Gender } & \multicolumn{2}{|c|}{ Mean age (yr) } & \multicolumn{5}{|c|}{ Intervention } \\
\hline & & & Exp. & Cont. & & $E G$ & CG & Types & $\begin{array}{l}\text { Duration } \\
\text { (weeks) }\end{array}$ & $\begin{array}{l}\text { Fre- } \\
\text { quency }\end{array}$ & $\begin{array}{l}\text { Time } \\
(\min )\end{array}$ & Intensity \\
\hline 1 & Duncan (1985) & USA & 44 & 12 & $M$ & \multicolumn{2}{|c|}{ All: 30.4} & Walking, jogging & 16 & 3 & 60 & 70 80 HRmax \\
\hline 2 & Urata (1987) & Japan & 10 & 10 & $\mathrm{M} / \mathrm{W}$ & 51.4 & 51 & Bicycle ergometer & 10 & 3 & 60 & $40 \sim 60$ V02 $\max$ \\
\hline 3a & Hagberg (1989a) & USA & 11 & 11 & NA & \multirow{2}{*}{\multicolumn{2}{|c|}{ All: 64.3}} & Walking, jogging & 37 & 3 & 50 & 50 VO2max \\
\hline $3 b$ & Hagberg (1989b) & & 11 & 11 & & & & & & & & $70 \sim 85$ VO2max \\
\hline $4 a$ & Kokkinos (1995a) & USA & 23 & 23 & M & 57 & 58 & Cycling & 16 & 3 & 60 & 60 80 HRmax \\
\hline $4 b$ & Kokkinos (1995b) & & 14 & 18 & & & & & 32 & & & \\
\hline 5 & Tanaka (1997) & USA & 12 & 6 & NA & 47 & 49 & Swimming & 10 & 3 & 45 & $60 \mathrm{HRR}$ \\
\hline 6 & Cooper (2000) & England & 48 & 42 & $\mathrm{M} / \mathrm{W}$ & 46 & 49 & Walking & 6 & 5 & 30 & Moderate \\
\hline 7 & Staffileno (2001) & USA & 9 & 9 & W & 57 & 62 & Walking & 8 & 5 & $50 \sim 60$ & 50 60 HRR \\
\hline 8 & Tsuda K (2003) & Japan & 8 & 8 & M & 46 & 49 & Walking, Jogging & 24 & 2 & 60 & NA \\
\hline $9 a$ & Tsai (2004a) & China & 50 & 52 & $\mathrm{M} / \mathrm{W}$ & 49 & 49 & Walking, Jogging & 6 & 3 & 50 & 60 70 HRmax \\
\hline $9 b$ & Tsai (2004b) & & & & & & & & 10 & & & \\
\hline 10 & Sohn (2007) & USA & 8 & 10 & $M / W$ & 47 & 42 & Walking & 26 & $5 \sim 7$ & 30 & NA \\
\hline 11 & Westhoff (2007) & Germany & 27 & 27 & $\mathrm{M} / \mathrm{W}$ & 67 & 69 & Treadmill exercise & 12 & 3 & $30 \sim 36$ & NA \\
\hline 12 & Westhoff (2008) & Germany & 12 & 12 & $M / W$ & 66 & 68 & Arm-cycling & 12 & 3 & 30 & NA \\
\hline $13 a$ & Guimaraes (2010a) & Brazil & 16 & 11 & $\mathrm{M} / \mathrm{W}$ & 50 & 47 & Treadmill (supervised) & 16 & 2 & 40 & $60 \mathrm{HRR}$ \\
\hline $13 b$ & Guimaraes (2010b) & & 16 & 11 & & 45 & 47 & $\begin{array}{l}\text { Treadmill } \\
\text { (non-supervised) }\end{array}$ & & & & \\
\hline $14 a$ & Knoepfli-Lenzin (2010a) & Switz- & 15 & 17 & M & \multirow{2}{*}{\multicolumn{2}{|c|}{ NA }} & Football & 12 & 3 & 60 & 75 85 HRmax \\
\hline $14 b$ & Knoepfli-Lenzin (2010b) & erland & 15 & 17 & & & & Running & & & & \\
\hline 15 & Andersen (2010) & Denmark & 13 & 9 & M & 47 & 48 & Football & 12 & 2 & 60 & 80 90 HRmax \\
\hline $16 a$ & Aminuddin (2011a) & Malaysia & 6 & 7 & W & 48 & 50 & Treadmill exercise & 4 & 2.4 & 45 & 70 80 HRR \\
\hline $16 b$ & Aminuddin (2011b) & & & & & & & & 8 & & & \\
\hline $17 a$ & Molmen-Hansen (2011a) & Norway & 25 & 25 & $\mathrm{M} / \mathrm{W}$ & 53 & 51 & $\begin{array}{l}\text { Walking/running } \\
\text { (interval) }\end{array}$ & 12 & 3 & 38 & 90 95 HRmax \\
\hline $17 \mathrm{~b}$ & $\begin{array}{l}\text { Moclmen-Hansen } \\
\text { (2011b) }\end{array}$ & & 23 & 25 & & 54 & 51 & $\begin{array}{l}\text { Walking/running } \\
\text { (continuous) }\end{array}$ & & & 47 & 70 HRmax \\
\hline 18 & Kim NJ (2011) & Korea & 12 & 12 & M & 70.5 & 70.4 & Dance & 26 & 2 & 90 & 11 14 RPE \\
\hline 19 & Dimeo (2012) & Germany & 24 & 26 & $M / W$ & 63 & 68 & Walking & $8 \sim 12$ & 3 & NA & NA \\
\hline $20 a$ & Krustrup (2012a) & Denmark & 22 & 11 & M & \multirow{2}{*}{\multicolumn{2}{|c|}{ All: 46}} & Football & 24 & 2 & 60 & 85 HRmax \\
\hline $20 b$ & Krustrup (2012b) & & 22 & 11 & & & & & 12 & & & \\
\hline 21 & Kwon OS (2013) & Korea & 10 & 10 & W & 58 & 56 & Aquarobic & 12 & 3 & 60 & 12 13 RPE \\
\hline 22 & Kim KH (2013) & Korea & 10 & 10 & W & 62 & 63 & Senior aerobic exercise & 8 & 3 & 60 & Low \\
\hline 23 & Sikiru et al (2014) & Nigeria & 112 & 105 & M & 59 & 58 & Bicycle ergometer & 8 & 3 & $45-60$ & $60 \sim 79$ HRR \\
\hline 24 & Kim JH (2014) & Korea & 8 & 8 & W & 65 & 64 & $\begin{array}{l}\text { Traditional dance of } \\
\text { Korea }\end{array}$ & 12 & 3 & 60 & 40 60 HRmax \\
\hline 25 & Maruf (2014) & Nigeria & 60 & 60 & NA & 51 & 55 & Aerobic dance & 12 & 3 & 45 & 50 70 HRR \\
\hline $26 a$ & $\operatorname{Arca}(2014 a)$ & Brazil & 19 & 14 & W & \multirow{2}{*}{\multicolumn{2}{|c|}{ NA }} & Deep water running & 12 & 3 & 50 & $50 \sim 60 \mathrm{HRR}$ \\
\hline $26 b$ & $\operatorname{Arca}(2014 b)$ & & 19 & 14 & & & & Stationary cycling & & & & \\
\hline 27 & Guimaraes (2014) & Brazil & 16 & 16 & $\mathrm{M} / \mathrm{W}$ & 55 & 52 & $\begin{array}{l}\text { Walking inside the } \\
\text { pool }\end{array}$ & 12 & 3 & 60 & 11 13 RPE \\
\hline $28 a$ & Mohr (2014a) & Faroe & 21 & 20 & W & 44 & 45 & Swimming & 15 & 3 & 60 & High \\
\hline $28 b$ & Mohr (2014b) & Island & 21 & 20 & & 46 & 45 & Swimming & & & & Moderate \\
\hline 29 & Lima et al (2017) & Brazil & 15 & 14 & $M / W$ & 68 & 70 & Treadmill exercise & 10 & 3 & 55 & NA \\
\hline 30 & Kaholokula (2017) & USA & 27 & 28 & $\mathrm{M} / \mathrm{W}$ & 55 & 55 & Hula & 12 & 2 & 20 & 40 85 V02max \\
\hline 31 & Motlagh (2017) & Iran & 39 & 39 & $M / W$ & 54 & 54 & Fasting walking & 12 & 5 & $>30$ & 40 60 HRR \\
\hline 32 & de Barros Cruz (2017) & Italy & 28 & 16 & $M / W$ & 54 & 52 & $\begin{array}{l}\text { Walking in heated } \\
\text { pool }\end{array}$ & 12 & 3 & 60 & 11 13 RPE \\
\hline 33 & Hong SK (2018) & Korea & 7 & 7 & M & 50 & 53 & $\begin{array}{l}\text { Fast walking and } \\
\text { running }\end{array}$ & 12 & 4 & 60 & 60 HRmax \\
\hline 34 & Izadi (2018) & Iran & 15 & 15 & $\mathrm{M} / \mathrm{W}$ & & & Ergometer cycle & 6 & 3 & 45 & 85 90 HRR \\
\hline 35 & Wong A (2018A) & Korea & 20 & 21 & W & 59 & 74 & Stair climbing & 12 & 4 & NA & 11 13 RPE \\
\hline 36 & Wong A (2018B) & Korea & 52 & 48 & W & 74 & 73 & Swimming & 20 & $3 \sim 4$ & $40 \sim 45$ & 70 75 HRmax \\
\hline 37 & He L et al (2018) & China & 23 & 23 & W & 58 & 57 & Walking & 12 & 3 & 60 & 45 50 VO2max \\
\hline
\end{tabular}

Cont. = Control group.; Exp. = Experimental group; HRmax = Maximal heart rate; HRR = Heart rate reserve; $M=M e n ; R P E=R a t i n g$ of perceived exertion; $\mathrm{VO} 2 \mathrm{max}=$ Maximum oxygen consumption; $\mathrm{W}=$ Women. 
way ( 1 article), Italy ( 1 article), and Faroe Islands ( 1 article). As to participants' gender, 10 studies $(27.0 \%)$ included women only, 9 studies (24.3\%) included men only, and 15 studies (40.5\%) included both women and men. Mean ages of the studies evenly ranged from 30 s to 70 s.

Of aerobic exercise types, intervention used in the majority of the studies was walking or running that included 20 studies (54.1\%) followed by water-based training (6 studies, 16.2\%), bike-riding (5 studies, 13.5\%) and aerobic dance or dance (5 studies, 13.5\%). Exercise intensity was assessed with \% VO2max (maximal oxygen consumption), \% HRmax (maximal heart rate), RPE (rating of perceived exertion), and \% HRR (heart rate reserve). Among the literature selected, 31 studies (83.8\%) provided exercise intensity and the rest did not (6 studies, 16.2\%). As to number of exercise per week, three times weekly (23 studies, 62.2\%) was applied the most. Intervention duration was applied variously between 4 weeks and 37 weeks although twelve-week duration (17 studies, 46.0\%) was used the most, and 6 months duration or longer was even applied in six studies $(16.2 \%)$

\section{Assessing risk of bias of individual studies}

As to risk of bias that may have occurred during randomization, 7 studies (18.9\%) were assessed as low risk, twenty-six (70.3\%) as some concerns, and four (10.8\%) as high risk. For deviation from the intended intervention, 21 studies (56.8\%) were assessed as low risk, fifteen (40.5\%) as some concerns, and one (2.7\%) as high risk. As to bias in relation to missing outcome data of study results, on the contrary, all of the studies were assessed as low risk indicating no article of all had any omission found. In the domain of measurement of the outcome, and selection of the reported result were assessed as low risk (Figure 2,

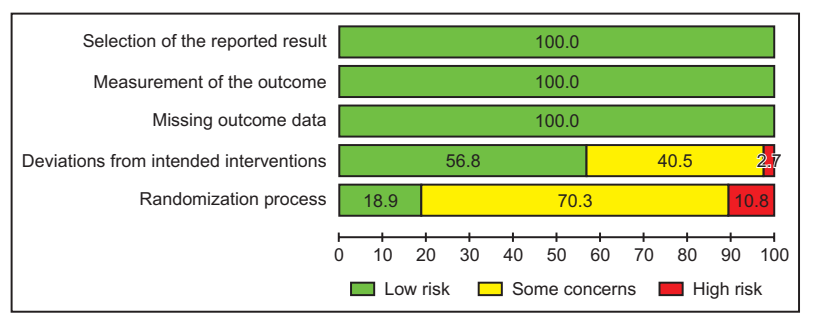

Figure 2. Risk of bias graph.
Appendix 2).

\section{Effects of aerobic exercise for hypertensive patients}

1) Systolic BP

Any article that included two different intervention methods was regarded as two different studies for the analysis, which made into 39 studies in total. The number of participants in exercise group was 958 and the number in controlled group was 855. Overall effect size of aerobic exercise intervention affecting systolic $\mathrm{BP}$ of hypertensive patients was $-8.29 \mathrm{mmHg}(95 \% \mathrm{CI}=$ -10.12 to -6.46$)$, which interprets to be statistically significant $(z=-8.86, p<.001)$ (Table 2, Figure 3A).

Effect sizes of different exercise types were $-6.96 \mathrm{mmHg}$ (95\% CI $=-8.44$ to -5.47$)$ for walking or running, -14.78 $\mathrm{mmHg}(95 \% \mathrm{CI}=-20.78$ to -8.78$)$ for water-based training, $-6.16 \mathrm{mmHg}(95 \% \mathrm{CI}=-10.40$ to -1.91$)$ for dance, and -9.37 $\mathrm{mmHg}(95 \% \mathrm{CI}=-15.80$ to -2.94$)$ for bike-riding, and exercise with the most dramatical change after intervention was water-based training, but all of them were statistically significant (Table 2).

As to exercise intensity, effect size was $-2.93 \mathrm{mmHg}(95 \% \mathrm{CI}=$ -7.25 to 1.39 ) for of low-intensity exercise, $-8.97 \mathrm{mmHg}$ (95\% $\mathrm{CI}=-11.11$ to -6.84$)$ for moderate-intensity exercise, and $-6.85 \mathrm{mmHg}(95 \% \mathrm{CI}=-12.03$ to -1.66$)$ for vigorous-intensity exercise, showing that effect size of low-intensity exercise was statistically non-significant while ones of moderate- and vigorous-intensity exercise were statistically significant, and effect size of moderate-intensity exercise was the greatest (Table 2).

Effect sizes depending on exercise frequency were -6.10 $\mathrm{mmHg}(95 \% \mathrm{CI}=-8.83$ to -3.37$)$ for twice weekly, -9.16 $\mathrm{mmHg}(95 \% \mathrm{CI}=-11.66$ to -6.66$)$ for three times weekly, and $-6.96 \mathrm{mmHg}(95 \% \mathrm{CI}=-9.27$ to -4.64$)$ for four or more times weekly, which would indicate statistical significance (Table 2).

Effect size of each intervention duration was $-3.04 \mathrm{mmHg}$ (95\% CI $=-5.14$ to -0.95$)$ for 4 7 weeks, $-9.12 \mathrm{mmHg}(95 \%$ $\mathrm{CI}=-14.09$ to -4.16$)$ for $8 \sim 11$ weeks, $-8.77 \mathrm{mmHg}(95 \% \mathrm{CI}=$ -11.06 to -6.49$)$ for $12 \sim 23$ weeks, and $-8.24 \mathrm{mmHg}(95 \% \mathrm{CI}=$ -10.77 to -6.27$)$ for 24 weeks or longer of exercise. The effect sizes of all groups were statistically significant and duration of 
Table 2. Effect Size of Blood Pressure by Exercise Characteristics

\begin{tabular}{|c|c|c|c|c|c|c|c|c|}
\hline \multirow{2}{*}{ Variables } & \multicolumn{4}{|c|}{ Systolic blood pressure } & \multicolumn{4}{|c|}{ Diastolic blood pressure } \\
\hline & Study (k) & $E C(n)$ & $C G(n)$ & Effect size $(95 \% \mathrm{Cl})(\mathrm{mmHg})$ & Study (k) & $E C(n)$ & $C G(n)$ & Effect size $(95 \% \mathrm{Cl})(\mathrm{mmHg})$ \\
\hline Total & 39 & 958 & 855 & $-8.29(-10.12$ to -6.46$)$ & 39 & 958 & 855 & $-5.19(-6.24$ to -4.14$)$ \\
\hline \multicolumn{9}{|l|}{ Exercise types } \\
\hline Walk or running & 22 & 511 & 445 & $-6.96(-8.44$ to -5.47$)$ & 22 & 511 & 445 & $-4.96(-6.37$ to -3.54$)$ \\
\hline Water base training & 6 & 137 & 110 & $-14.78(-20.78$ to -8.78$)$ & 6 & 137 & 110 & $-7.78(-8.85$ to -6.71$)$ \\
\hline Dace & 5 & 115 & 113 & $-6.16(-10.40$ to -1.91$)$ & 5 & 115 & 113 & $-3.65(-6.33$ to -0.98$)$ \\
\hline Bike-riding & 6 & 195 & 187 & $-9.37(-15.80$ to -2.94$)$ & 6 & 195 & 187 & $-5.75(-7.54$ to -3.95$)$ \\
\hline \multicolumn{9}{|l|}{ Exercise intensity } \\
\hline Low & 2 & 18 & 18 & $-2.93(-7.25$ to 1.39$)$ & 2 & 18 & 18 & $-1.62(-3.52$ to 0.28$)$ \\
\hline Moderate & 22 & 608 & 538 & $-8.97(-11.11$ to -6.84$)$ & 22 & 608 & 538 & $-5.75(-7.18$ to -4.32$)$ \\
\hline Vigorous & 9 & 241 & 202 & $-6.85(-12.03$ to -1.66$)$ & 9 & 241 & 202 & $-4.36(-5.94$ to -2.79$)$ \\
\hline \multicolumn{9}{|l|}{ Exercise frequency } \\
\hline 2 times/week & 7 & 112 & 85 & $-6.10(-8.83$ to -3.37$)$ & 7 & 112 & 85 & $-4.38(-7.09$ to -1.66$)$ \\
\hline 3 times/week & 26 & 716 & 645 & $-9.16(-11.66$ to -6.66$)$ & 26 & 716 & 645 & $-5.55(-6.87$ to -4.23$)$ \\
\hline$\geq 4$ times/week & 6 & 130 & 126 & $-6.96(-9.27$ to -4.64$)$ & 6 & 130 & 126 & $-4.50(-6.80$ to -2.20$)$ \\
\hline \multicolumn{9}{|l|}{ Exercise duration } \\
\hline 4 7 weeks & 3 & 114 & 104 & $-3.04(-5.14$ to -0.95$)$ & 3 & 114 & 104 & $-3.58(-4.77$ to -2.39$)$ \\
\hline $8 \sim 11$ weeks & 7 & 234 & 220 & $-9.12(-14.09$ to -4.16$)$ & 7 & 234 & 220 & $-5.42(-7.95$ to -2.89$)$ \\
\hline 12 23 weeks & 22 & 522 & 454 & $-8.77(-11.06$ to -6.49$)$ & 22 & 522 & 454 & $-4.84(-6.40$ to -3.28$)$ \\
\hline$\geq 24$ weeks & 7 & 88 & 77 & $-8.24(-10.77$ to -6.27$)$ & 7 & 88 & 77 & $-7.15(-9.14$ to -5.15$)$ \\
\hline
\end{tabular}

Cont. $=$ Control group; Exp. $=$ Experimental group.

8 11 weeks showed the greatest effect size (Table 2).

\section{2) Diastolic BP}

Mean effect size of aerobic-exercise affecting diastolic BP of hypertensive patients was $-5.19 \mathrm{mmHg}(95 \% \mathrm{CI}=-6.24$ to $-4.14)$, and was statistically significant $(z=-9.69, p<.001)$ (Table 2, Figure 3B).

Effect sizes of different exercise types were $-4.96 \mathrm{mmHg}$ (95\% CI $=-6.37$ to -3.54$]$ for walking or running, -7.78 $\mathrm{mmHg}(95 \% \mathrm{CI}=-8.85$ to -6.71$)$ for water-based training, $-3.65 \mathrm{mmHg}(95 \% \mathrm{CI}=-6.33$ to -0.98$)$ for dance, and -5.75 $\mathrm{mmHg}(95 \% \mathrm{CI}=-7.54$ to -3.95$)$ for bike-riding and all of them had positive impact on reduction of diastolic BP (Table 2).

As to exercise intensity, effect size was $-1.62 \mathrm{mmHg}(95 \% \mathrm{CI}=$ -3.52 to 0.28$)$ for low-intensity exercise, $-5.75 \mathrm{mmHg}(95 \% \mathrm{CI}=$ -7.18 to -4.32$)$ for moderate-intensity exercise, and -4.36 $\mathrm{mmHg}(95 \% \mathrm{CI}=-5.94$ to -2.79$)$ for vigorous-intensity exercise. Same as systolic BP, effect size of low-intensity exercise was not statistically significant, and moderate-intensity exercise intervention had the most impact on reduction of diastolic BP (Table 2).
Effect sizes depending on exercise frequency were -4.38 $\mathrm{mmHg}(95 \% \mathrm{CI}=-7.09$ to -1.66$)$ for twice weekly, -5.55 $\mathrm{mmHg}(95 \% \mathrm{CI}=-6.87$ to -4.23$)$ for three times weekly, and $-4.50 \mathrm{mmHg}(95 \% \mathrm{CI}=-6.80$ to -2.20$)$ for four times weekly, suggesting that only twice of aerobic exercise weekly would still have an effect on reducing diastolic BP (Table 2).

Effect size of each intervention duration was $-3.58 \mathrm{mmHg}$ (95\% CI $=-4.77$ to -2.39$)$ for $4 \sim 7$ weeks, $-5.42 \mathrm{mmHg}$ (95\% $\mathrm{CI}=-7.95$ to -2.89$)$ for $8 \sim 11$ weeks, $-4.84 \mathrm{mmHg}(95 \% \mathrm{CI}=$ -6.40 to -3.28$)$ for $12 \sim 23$ weeks, and $-7.15 \mathrm{mmHg}(95 \% \mathrm{CI}=$ -9.14 to -5.15$)$ for 24 weeks or longer of exercise. The effect sizes of all groups were statistically significant and duration of 24 weeks or longer had the most impact on lowering diastolic BP (Table 2).

\section{3) Heart rate}

The number of studies that included effect size of heart rate was thirty-one with 626 subjects in exercise group and 535 in controlled group. Mean effect size of aerobic-exercise affecting heart rate of hypertensive patients was -4.22 beats $/ \mathrm{min}$ ( $95 \% \mathrm{CI}=$ -5.36 to -3.09$)$, and was statistically significant $(z=-7.28$, 


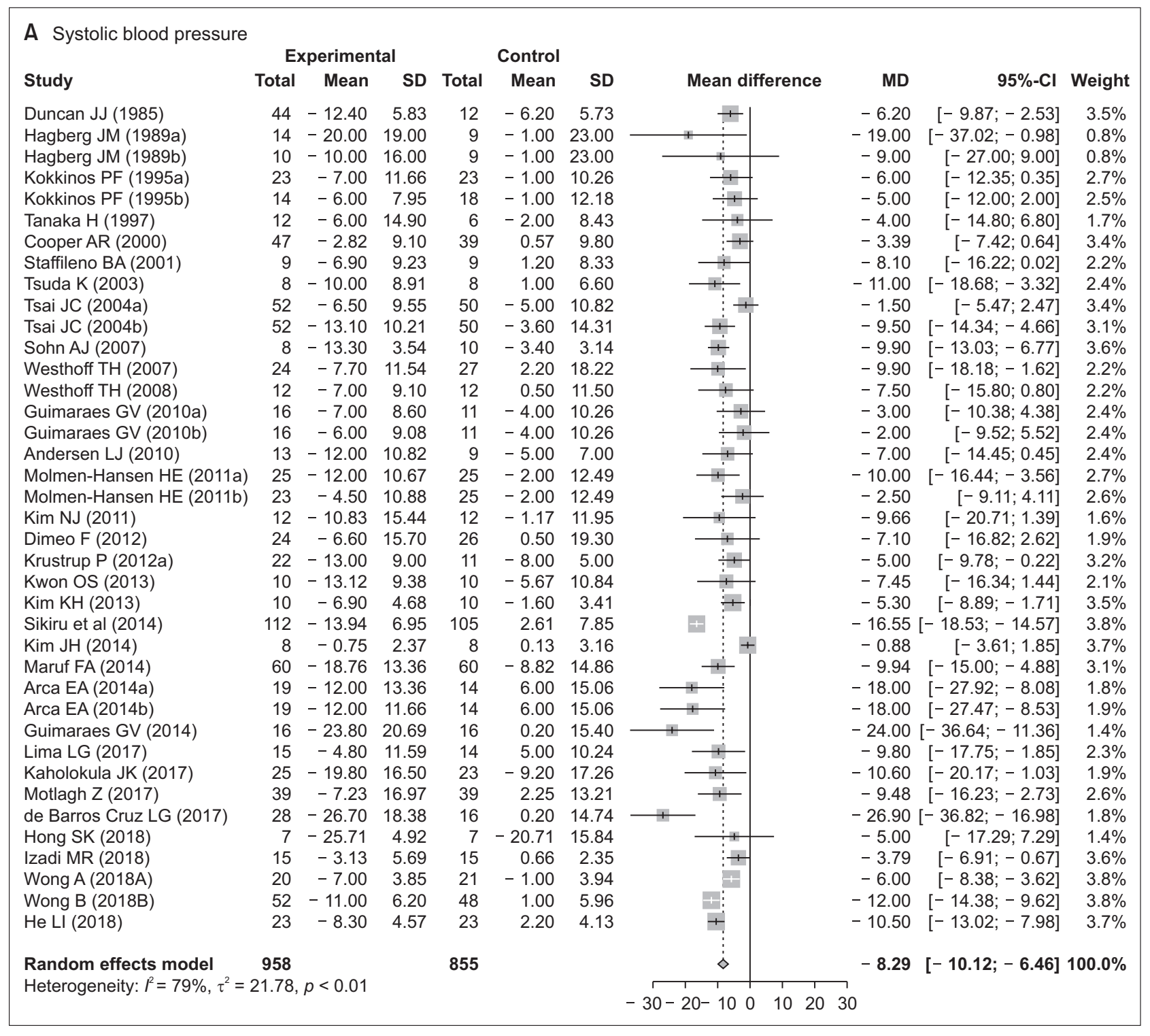

Figure 3. Forest plots of the effects of aerobic exercise.

$p<.001)$ (Figure 3C).

\section{Heterogeneity of effect size and analysis of moderator effects}

Heterogeneity between the studies of systolic BP was $I^{2}=79 \%$ $(\mathrm{Q}=183.05, p<.001)$ which indicates a high degree (Figure 3A). Analysis results of moderator effects showed that exercise type $\left(\mathrm{Q}=8.72\right.$, df $\left.=3, p=.033, \mathrm{R}^{2}=24.1 \%\right)$ had impact on effect size of systolic BP. Any of the other factors including exercise intensity $(\mathrm{Q}=3.10$, $\mathrm{df}=2, p=.212)$, frequency $(\mathrm{Q}=1.27$, $\mathrm{df}=2, p=.529)$, and duration $(\mathrm{Q}=4.75, \mathrm{df}=3, p=.191)$ was not statistically significant. As results of moderator analysis, characteristic factors of patients such as gender $(Q=0.03$, $p=.868)$, medication $(\mathrm{Q}=0.46, p=.500)$, age $(\mathrm{b}=-0.12$, $Z=-1.19, p=.234)$ were also not statistically significant.

Heterogeneity among the studies including diastolic BP was $I^{2}=79 \%(\mathrm{Q}=183.57, p<.001)$ which indicates a high degree of heterogeneity (Figure 3B). Analysis results of moderator effects showed that all exercise factors including exercise types $(\mathrm{Q}=3.81, \mathrm{df}=3, p=.283)$, exercise intensity $(\mathrm{Q}=5.23, \mathrm{df}=2$, $p=.073)$, frequency $(\mathrm{Q}=0.92, \mathrm{df}=2, p=.633)$, and duration $(\mathrm{Q}=3.61, \mathrm{df}=3, p=.307)$ had no impact on effect size of dia- 


\begin{tabular}{|c|c|c|c|c|c|c|c|c|c|c|c|}
\hline & \multicolumn{6}{|c|}{ B Diastolic blood pressure } & \multirow{2}{*}{\multicolumn{2}{|c|}{ Mean difference }} & \multirow[b]{2}{*}{ MD } & \multirow[b]{2}{*}{$95 \%-\mathrm{Cl}$} & \multirow[b]{2}{*}{ Weight } \\
\hline Study & Total & Mean & SD & Total & Mean & SD & & & & & \\
\hline Duncan JJ (1985) & 44 & -7.10 & 2.98 & 12 & 2.90 & 4.38 & $\longrightarrow$ & & -10.00 & {$[-12.63 ;-7.37]$} & $3.2 \%$ \\
\hline Hagberg JM (1989a) & 14 & -12.00 & 13.40 & 9 & -2.00 & 10.70 & & & -10.00 & {$[-19.91 ;-0.09]$} & $0.9 \%$ \\
\hline Hagberg JM (1989b) & 10 & -11.00 & 4.80 & 9 & -2.00 & 10.70 & + & & -9.00 & {$[-16.60 ;-1.40]$} & $1.3 \%$ \\
\hline Kokkinos PF (1995a) & 23 & -5.00 & 5.69 & 23 & 2.00 & 4.95 & $\longrightarrow$ & & -7.00 & {$[-10.08 ;-3.92]$} & $3.0 \%$ \\
\hline Kokkinos PF (1995b) & 14 & -4.00 & 4.95 & 18 & 1.00 & 4.95 & 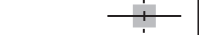 & & -5.00 & {$[-8.46 ;-1.54]$} & $2.8 \%$ \\
\hline Tanaka H (1997) & 12 & -5.00 & 9.62 & 6 & -3.00 & 5.50 & & & -2.00 & {$[-9.00 ; 5.00]$} & $1.4 \%$ \\
\hline Cooper AR (2000) & 47 & -1.85 & 6.20 & 39 & 0.91 & 7.70 & & & -2.76 & {$[-5.76 ; 0.24]$} & $3.1 \%$ \\
\hline Staffileno BA (2001) & 9 & -3.40 & 7.01 & 9 & 1.20 & 8.11 & & - & -4.60 & {$[-11.60 ; 2.40]$} & $1.4 \%$ \\
\hline Tsuda K (2003) & 8 & -6.00 & 4.12 & 8 & -1.00 & 9.88 & & & -5.00 & {$[-12.42 ; 2.42]$} & $1.3 \%$ \\
\hline Tsai JC (2004a) & 52 & -3.20 & 5.20 & 50 & 1.30 & 4.58 & & & -4.50 & {$[-6.40 ;-2.60]$} & $3.6 \%$ \\
\hline Tsai JC (2004b) & 52 & -6.30 & 5.80 & 50 & 4.00 & 4.58 & + & & -10.30 & {$[-12.32 ;-8.28]$} & $3.5 \%$ \\
\hline Sohn AJ (2007) & 8 & -7.10 & 2.24 & 10 & 0.90 & 2.02 & + & & -8.00 & {$[-10.00 ;-6.00]$} & $3.5 \%$ \\
\hline Westhoff TH (2007) & 24 & -4.30 & 6.35 & 27 & 2.30 & 9.23 & $\longrightarrow:$ & & -6.60 & {$[-10.91 ;-2.29]$} & $2.4 \%$ \\
\hline Westhoff TH (2008) & 12 & -5.90 & 7.40 & 12 & 3.70 & 8.10 & + & & -9.60 & {$[-15.81 ;-3.39]$} & $1.7 \%$ \\
\hline Guimaraes GV (2010a) & 16 & -3.00 & 6.27 & 11 & -3.00 & 7.87 & & & 0.00 & {$[-5.57 ; 5.57]$} & $1.9 \%$ \\
\hline Guimaraes GV (2010b) & 16 & -4.00 & 5.69 & 11 & -3.00 & 7.87 & & & -1.00 & {$[-6.42 ; 4.42]$} & $1.9 \%$ \\
\hline Andersen LJ (2010) & 13 & -7.00 & 3.61 & 9 & -3.00 & 4.49 & & & -4.00 & {$[-7.53 ;-0.47]$} & $2.8 \%$ \\
\hline Molmen-Hansen HE (2011a) & 25 & -8.00 & 6.10 & 25 & -2.00 & 7.98 & 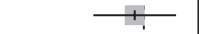 & & -6.00 & {$[-9.94 ;-2.06]$} & $2.6 \%$ \\
\hline Molmen-Hansen HE (2011b) & 23 & -3.50 & 5.83 & 25 & -2.00 & 7.98 & & & -1.50 & {$[-5.43 ; 2.43]$} & $2.6 \%$ \\
\hline Kim NJ (2011) & 12 & -12.58 & 8.73 & 12 & 0.09 & 3.70 & + & & -12.67 & {$[-18.03 ;-7.31]$} & $2.0 \%$ \\
\hline Dimeo F (2012) & 24 & -2.70 & 8.00 & 26 & -0.60 & 11.00 & 1 & & -2.10 & {$[-7.40 ; 3.20]$} & $2.0 \%$ \\
\hline Krustrup P (2012a) & 22 & -8.00 & 5.00 & 11 & -3.00 & 3.00 & $\div$ & & -5.00 & {$[-7.74 ;-2.26]$} & $3.2 \%$ \\
\hline Kwon OS (2013) & 10 & -10.44 & 6.93 & 10 & -5.22 & 7.91 & & & -5.22 & {$[-11.74 ; 1.30]$} & $1.6 \%$ \\
\hline Kim KH (2013) & 10 & -3.40 & 2.12 & 10 & -0.70 & 2.16 & -1 & & -2.70 & {$[-4.58 ;-0.82]$} & $3.6 \%$ \\
\hline Sikiru et al (2014) & 112 & -7.41 & 6.26 & 105 & -1.07 & 1.76 & + & & -6.34 & {$[-7.55 ;-5.13]$} & $3.9 \%$ \\
\hline Kim JH (2014) & 8 & -0.62 & 1.43 & 8 & 0.13 & 1.4 & + & & -0.75 & {$[-2.16 ; 0.66]$} & $3.8 \%$ \\
\hline Maruf FA (2014) & 60 & -8.98 & 9.84 & 60 & -5.60 & 3.79 & & & -3.38 & {$[-6.05 ;-0.71]$} & $3.2 \%$ \\
\hline Arca EA (2014a) & 19 & -2.00 & 9.03 & 14 & 3.00 & 10.41 & & & -5.00 & {$[-11.80 ; 1.80]$} & $1.5 \%$ \\
\hline Arca EA (2014b) & 19 & -5.00 & 6.73 & 14 & 3.00 & 10.41 & +1 & & -8.00 & {$[-14.24 ;-1.76]$} & $1.7 \%$ \\
\hline Guimaraes GV (2014) & 16 & -5.90 & 11.19 & 16 & 0.80 & 7.31 & 世! & & -6.70 & {$[-13.25 ;-0.15]$} & $1.6 \%$ \\
\hline Lima LG (2017) & 15 & -4.50 & 4.23 & 14 & 1.80 & 6.19 & ए; & & -6.30 & {$[-10.19 ;-2.41]$} & $2.6 \%$ \\
\hline Kaholokula JK (2017) & 25 & -6.10 & 8.50 & 23 & -3.50 & 11.51 & 1 & & -2.60 & {$[-8.36 ; 3.16]$} & $1.8 \%$ \\
\hline Motlagh Z (2017) & 39 & -3.05 & 8.52 & 39 & 1.46 & 6.43 & i & & -4.51 & {$[-7.86 ;-1.16]$} & $2.9 \%$ \\
\hline de Barros Cruz LG (2017) & 28 & -7.10 & 1.76 & 16 & 0.70 & 1.75 & $+\vdots$ & & -7.80 & {$[-8.88 ;-6.72]$} & $3.9 \%$ \\
\hline Hong SK (2018) & 7 & -8.43 & 6.81 & 7 & -5.72 & 5.96 & $\begin{array}{c:cc} & 1 \\
& 1\end{array}$ & & -2.71 & {$[-9.42 ; 4.00]$} & $1.5 \%$ \\
\hline Izadi MR (2018) & 15 & -2.13 & 2.58 & 15 & 0.93 & 2.40 & $\vdots-+$ & & -3.06 & {$[-4.84 ;-1.28]$} & $3.6 \%$ \\
\hline Wong A (2018A) & 20 & -3.00 & 3.35 & 21 & 0.00 & 3.43 & & & -3.00 & {$[-5.07 ;-0.93]$} & $3.5 \%$ \\
\hline Wong B (2018B) & 52 & -9.00 & 5.40 & 48 & 0.00 & 5.18 & + & & -9.00 & {$[-11.07 ;-6.93]$} & $3.5 \%$ \\
\hline He LI (2018) & 23 & -1.10 & 3.34 & 23 & 0.80 & 2.80 & 7 & & -1.90 & {$[-3.68 ;-0.12]$} & $3.6 \%$ \\
\hline & & & & 855 & & & $\Delta$ & & -5.19 & {$[-6.24 ;-4.14]$} & $100.0 \%$ \\
\hline \multicolumn{4}{|c|}{ Heterogeneity: $l^{2}=79 \%, \tau^{2}=7.08, p<0.01$} & & & & & & 10 & & \\
\hline
\end{tabular}

Figure 3. Continued.

stolic BP. Also, all patient characteristic factors such as gender $(\mathrm{Q}=3.27, p=.071)$, medication $(\mathrm{Q}=2.84, p=.092)$, age $(\mathrm{b}=-0.01, z=-0.19, p=.847)$ were not statistically significant.

Studies including heart rate had moderate heterogeneity with $I^{2}=60 \%(\mathrm{Q}=75.57, p<.001)$ (Figure $\left.3 \mathrm{C}\right)$. Analysis results of moderator effects showed that all factors including exercise types $(\mathrm{Q}=2.74, \mathrm{df}=3, p=.434)$, intensity $(\mathrm{Q}=0.70, \mathrm{df}=2, p=.703)$, frequency $(\mathrm{Q}=0.94$, $\mathrm{df}=2, p=.625)$, duration $(\mathrm{Q}=6.64$, $\mathrm{df}=3, p=.084)$, gender $(\mathrm{Q}=0.03, p=.866)$, medication $(\mathrm{Q}=0.00, p=.998)$, and age $(\mathrm{b}=-0.09, z=-1.40, p=.163)$ were not statistically significant.

\section{Publication bias}

Systolic BP, diastolic BP and heart rate were all symmetrically distributed (Appendix 3). The results of Egger's regression were bias $=0.22(\mathrm{t}=0.32, \mathrm{df}=37, p=.748)$ in systolic $\mathrm{BP}$, bias $=0.18$ $(\mathrm{t}=0.26, \mathrm{df}=37, p=.795)$ in diastolic $\mathrm{BP}$, and bias $=-0.59$ $(t=-1.00, \mathrm{df}=29, p=.325)$ in heart rate, which suggests there was no bias among the test items. 


\begin{tabular}{|c|c|c|c|c|c|c|c|c|c|c|}
\hline \multicolumn{11}{|l|}{ C Heart rate } \\
\hline Study & Total & Mean & SD & Total & Mean & SD & Mean difference & MD & $95 \%-\mathrm{Cl}$ & Weight \\
\hline Duncan JJ (1985) & 41 & -8.50 & 9.96 & 11 & -0.50 & 6.13 & $1:-$ & -8.00 & {$[-12.73 ;-3.27]$} & $3.1 \%$ \\
\hline Urata H (1987) & 10 & -1.90 & 5.09 & 10 & -2.10 & 5.61 & & 0.20 & {$[-4.50 ; 4.90]$} & $3.1 \%$ \\
\hline Hagberg JM (1989a) & 14 & -13.00 & 7.29 & 9 & 1.00 & 4.29 & + & -14.00 & {$[-18.74 ;-9.26]$} & $3.1 \%$ \\
\hline Hagberg JM (1989b) & 10 & -8.00 & 6.35 & 9 & 1.00 & 4.29 & $\longrightarrow$ & -9.00 & {$[-13.83 ;-4.17]$} & $3.0 \%$ \\
\hline Kokkinos PF (1995a) & 23 & -2.00 & 6.85 & 23 & 2.00 & 6.85 & i & -4.00 & {$[-7.96 ;-0.04]$} & $3.7 \%$ \\
\hline Tanaka H (1997) & 12 & -10.10 & 9.43 & 6 & -1.70 & 8.80 & t! & -8.40 & {$[-17.23 ; 0.43]$} & $1.3 \%$ \\
\hline Tsuda K (2003) & 8 & -1.00 & 5.99 & 8 & -2.00 & 7.98 & & 1.00 & {$[-5.91 ; 7.91]$} & $1.9 \%$ \\
\hline Tsai JC (2004a) & 52 & 1.80 & 8.51 & 50 & 1.60 & 8.96 & & 0.20 & {$[-3.19 ; 3.59]$} & $4.2 \%$ \\
\hline Tsai JC (2004b) & 52 & -2.20 & 7.35 & 50 & 2.20 & 8.91 & $-i$ & -4.40 & {$[-7.58 ;-1.22]$} & $4.4 \%$ \\
\hline Westhoff TH (2008) & 12 & -1.20 & 8.60 & 12 & 1.90 & 9.50 & $\vdots$ & -3.10 & {$[-10.35 ; 4.15]$} & $1.8 \%$ \\
\hline Guimaraes GV (2010a) & 16 & -2.00 & 6.37 & 11 & -1.00 & 5.33 & & -1.00 & {$[-5.43 ; 3.43]$} & $3.3 \%$ \\
\hline Guimaraes GV (2010b) & 16 & -2.00 & 8.81 & 11 & -1.00 & 5.33 & & -1.00 & {$[-6.34 ; 4.34]$} & $2.7 \%$ \\
\hline Knoepfli-Lenzin C (2010a) & 15 & -7.00 & 8.47 & 17 & -6.00 & 6.09 & \begin{tabular}{ll}
1 \\
\hdashline & 1
\end{tabular} & -1.00 & {$[-6.17 ; 4.17]$} & $2.8 \%$ \\
\hline Knoepfli-Lenzin C (2010b) & 15 & -9.00 & 4.93 & 17 & -6.00 & 6.09 & & -3.00 & {$[-6.82 ; 0.82]$} & $3.8 \%$ \\
\hline Andersen LJ (2010) & 13 & -12.00 & 7.21 & 9 & 1.00 & 6.85 & + & -13.00 & {$[-18.95 ;-7.05]$} & $2.4 \%$ \\
\hline Aminuddin A (2011a) & 6 & -4.00 & 3.75 & 7 & 3.00 & 7.13 & $\longrightarrow:$ & -7.00 & {$[-13.07 ;-0.93]$} & $2.3 \%$ \\
\hline Aminuddin A (2011b) & 6 & -4.00 & 3.75 & 7 & 3.15 & 7.15 & $\begin{array}{l:l}1 & \vdots \\
\end{array}$ & -7.15 & {$[-13.24 ;-1.06]$} & $2.3 \%$ \\
\hline Molmen-Hansen HE (2011a) & 25 & -3.70 & 5.97 & 25 & 0.30 & 5.80 & $\div$ & -4.00 & {$[-7.26 ;-0.74]$} & $4.3 \%$ \\
\hline Molmen-Hansen HE (2011b) & 23 & -0.20 & 5.64 & 25 & 0.30 & 5.80 & & -0.50 & {$[-3.74 ; 2.74]$} & $4.3 \%$ \\
\hline Krustrup P (2012a) & 22 & -8.00 & 11.00 & 11 & -3.00 & 9.00 & i & -5.00 & {$[-12.03 ; 2.03]$} & $1.9 \%$ \\
\hline Krustrup P (2012b) & 22 & -7.00 & 7.84 & 11 & 0.00 & 6.85 & $1 \vdots$ & -7.00 & {$[-12.21 ;-1.79]$} & $2.8 \%$ \\
\hline Kim KH (2013) & 10 & -12.10 & 7.55 & 10 & -4.20 & 8.80 & $\begin{array}{l:l}1 \\
-1\end{array}$ & -7.90 & {$[-15.09 ;-0.71]$} & $1.8 \%$ \\
\hline Guimaraes GV (2014) & 16 & -3.60 & 13.07 & 16 & 1.70 & 10.75 & & -5.30 & {$[-13.59 ; 2.99]$} & $1.5 \%$ \\
\hline Mohr M (2014a) & 21 & -5.00 & 6.98 & 20 & -3.00 & 6.81 & \begin{tabular}{ccc}
1 \\
\hdashline
\end{tabular} & -2.00 & {$[-6.22 ; 2.22]$} & $3.5 \%$ \\
\hline Mohr M (2014b) & 21 & -5.00 & 9.70 & 20 & -3.00 & 6.81 & $\begin{array}{c}1 \\
\vdots\end{array}$ & -2.00 & {$[-7.11 ; 3.11]$} & $2.8 \%$ \\
\hline de Barros Cruz LG (2017) & 28 & -3.30 & 2.40 & 16 & 1.60 & 2.86 & + & -4.90 & {$[-6.56 ;-3.24]$} & $5.8 \%$ \\
\hline Hong SK (2018) & 7 & -6.29 & 5.06 & 7 & -2.72 & 7.78 & \begin{tabular}{l|l}
$i$ \\
$i$
\end{tabular} & -3.57 & {$[-10.45 ; 3.31]$} & $1.9 \%$ \\
\hline Izadi MR (2018) & 15 & -2.06 & 1.09 & 15 & -0.20 & 3.25 & $\vdots+$ & -1.86 & {$[-3.59 ;-0.13]$} & $5.7 \%$ \\
\hline Wong A (2018A) & 20 & -2.00 & 3.41 & 21 & 0.00 & 3.49 & 1 & -2.00 & {$[-4.11 ; 0.11]$} & $5.4 \%$ \\
\hline Wong B (2018B) & 52 & -7.00 & 10.98 & 48 & 1.00 & 10.55 & 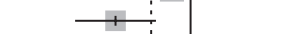 & -8.00 & {$[-12.22 ;-3.78]$} & $3.5 \%$ \\
\hline He LI (2018) & 23 & -3.60 & 2.24 & 23 & 1.50 & 3.05 & + & -5.10 & {$[-6.65 ;-3.55]$} & $5.9 \%$ \\
\hline \multirow{2}{*}{\multicolumn{7}{|c|}{ Heterogeneity: $I^{2}=60 \%, \tau^{2}=5.09, p<0.01$}} & $\diamond$ & -4.22 & {$[-5.36 ;-3.09]$} & $100.0 \%$ \\
\hline & & & & & & & 5 & & & \\
\hline
\end{tabular}

Figure 3. Continued.

\section{DISCUSSION}

In order to examine closely the effects of aerobic-exercise intervention on $\mathrm{BP}$ and $\mathrm{HR}$ of patients with hypertension, in this study, a systematic review and meta-analysis have been performed. The total number of studies included in the systematic review was thirty-seven, which represent that a considerable number of studies of effects of aerobic exercise on hypertensive patients have consistently been conducted. Especially articles published after 2010 comprised $67.6 \%$ of all the studies selected, and this suggests that studies of effects of aerobic exercise on hypertensive patients have aggressively been carried out in recent years. Regarding types of aerobic exercise, exercise including walking and running made up more than half at $54.1 \%$. Börjesson et al.'s [12] systematic review including 27 studies and of Whelton et al.'s [16] study for meta-analysis reported similar results to our study. It is presumably because those types of exercise can be simply prepared, cost-efficiently used and easily accessed [23]. Another feature found in the systematic review was that participants of more than half i.e. four out of 6 studies of water-based training were women-only, and no studies with men-only participants have been found. Water-based training was the most effective in reducing blood pressure, but it was only for women, so it is necessary to investigate whether there is a difference by gender. Also, participants of three out of 5 studies of dance were elderly or women. Such findings suggest that types of exercise applied differs depending on the characteristics of participants. Although our results show effect size of BP was different by types of exercise, all types of aerobic exercise were found to be effective to lower BP, and therefore it would be desirable for an optimal type of aerobic exercise to be recommended to hypertensive patients considering their preference. 
Over two-thirds of the literature selected in this study used moderate-intensity exercise that accorded with Börjesson et al's [12] study that reported a majority of literature applied moderate-intensity intervention. This is presumably because ACSM generally recommends its moderate-intensity to patients with hypertension rather than prohibiting aerobic exercise. But vigorous-intensity exercise was also effective, so it may recommended with considering the risk to benefit ratio.

Effect sizes of systolic and diastolic BP after aerobic exercise were $-8.29 \mathrm{mmHg}$ and $-5.19 \mathrm{mmHg}$ respectively, similarly to some preceding studies $[13,14]$ that performed meta-analysis of aerobic-exercise effects on BP. Aerobic exercise may decrease BP by reducing sympathetic activation, vasoconstrictor tone of the vascular endothelial cells and cardiac output, and increasing vessel diameter, which would lead to reduction of peripheral vascular resistance [24,25].

In regards to types of exercise, all types of aerobic exercise including bike-riding, dance, walking/running, and water-based training helped lower both systolic and diastolic BP. The finding is meaningful that all types of aerobic exercise had effects on reduction of BP. In order to induce continuous and active participation in aerobic exercise, various environmental factors such as provision of exercise information, removal of exercise obstacles, and consideration of individual differences must be considered, but the autonomy of individuals participating in exercise, that is, self-determination, is an important factor. The group who chose the preferred type of exercise, that is, the group with high self-determination, perceived exercise positively, had high exercise persistence, and had a high physical and physiological effects [26]. Therefore it would be advisable, based on scientific ground, to provide selections of various aerobic-exercise types depending on each patient's preference. For example, a patient who is a senior or has a joint health problem is recommended to try water-based training rather than walking or running that can put stress on weight-bearing joints. Regular aerobic exercise help lower BP, and accordingly it is very important to generate excitement about the exercise. In other words, patients' engagement rate would increase by suggesting their preferred type of aerobic-exercise intervention to each individual [27].

As to effect size by exercise intensity, low-intensity aerobic exercise had no impact on reduction of systolic and diastolic BP, whereas moderate- and vigorous-intensity had an effect. Moderate-intensity exercise for hypertensive patients also is recommended by ACSM. But the results differ from ones of Whelton et al. [16] that low-, moderate- and vigorous-intensity exercises were all effective to lower BP. In this study [16], only 19 out of 47 studies were subject to hypertension. And when analyzing the difference in $\mathrm{BP}$ according to exercise intensity subgroup, it was not mentioned how many hypertensive participants were included. Therefore, it is not recommendable that low-intensity aerobic exercise is effective in hypertensive patients.

In terms of effect size by exercise frequency, each group who performed exercise twice, three times, or four times or more per week had the benefit of lowering systolic and diastolic BP although intergroup differences were statistically non-significant. Amount of exercise is associated with the product of frequency, intensity, and time [8]. Unexpectedly, participants who performed exercise twice weekly were found to have effect size as large as ones of groups who participated in exercise three or four times weekly. This is presumably because two-thirds of articles in twice-a-week groups performed vigorous-intensity exercise.

As to effect size by exercise duration, both systolic and diastolic BP significantly decreased in all groups, and aerobic exercise that lasts more than about 8 weeks may have a better antihypertensive effect. These results correspond to ones of the preceding studies that represented $\mathrm{BP}$ would begin to decrease 6 8 weeks following onset of exercise [28]. But, our results were different from Cao et al. [17] that compared three groups of exercise duration divided into less than 8 weeks, 8 12 weeks, and more than 12 weeks, with results that group of less than 8 weeks had the largest decrease in $\mathrm{BP}$, and longer duration led to smaller blood-pressure-lowering effects. However, Cao et al. [17] pointed out their limitation that very small number of literatured was only included for analysis.

Thus, selected exercise according to individual's preference should be regularly performed for 8 weeks or longer three times weekly with moderate-intensity or twice weekly with vigorous-intensity in order to maximize effects of aerobic exercise on BP.

Mean effect size of heart rate following aerobic exercise was -4.22 beats/min, which showed aerobic exercise helped to decrease heart rate. Although there have been a considerable num- 
ber of individual studies regarding effects of aerobic exercise on heart rate of hypertensive patients, only one of them has conucted meta-analysis, and its result showed the effect size was -4.94 beats/min [17], which corresponded to our analysis results. Higher heart rate is linked with cardiovascular disease as well as hypertension, and therefore it would be very meaningful result that aerobic exercise decreased heart rate of patients with hypertension [29]. Sympathetic activity, in particular, that commonly occurs in hypertensive patients may be controlled and parasympathetic nervous system may be activated, which would result in heart rate deceleration [30].

There have been a number of studies that performed meta-analysis depending on categories of exercise (e.g. aerobic exercise, strength exercise, and complex exercise), but only few studies verified the effects based on classified variables including types, intensity, frequency and duration of aerobic exercise. In this light, our study that computed each effect size depending on aerobic exercise characteristics has implications. Our findings will be the basis of intervention for patients with hypertension who can select any preferred type of aerobic exercise among walking, running, bike-riding, dance, swimming or aquarobic, etc. It is also expected that this results will be a guidance of interventions or studies of aerobic exercise for hypertensive patients.

Our study has several limitations. First, this study included articles published in Korean or English only, and therefore studies that would possibly reflect characteristics of participants from other cultural areas may have unfortunately been left out. Second, there were only two articles that included low-intensity exercise, and so direct comparison of effect sizes was restricted unlike moderate- or vigorous-intensity exercise. Third, although RCTs were only included, effect-size heterogeneity of exercise types, intensity, frequency and duration was measured to be moderate or higher. Therefore, the results should be interpreted with caution. Still, our results are considered highly reliable because RCT studies with considerable quality of evidence were only selected in this study and any publication bias was not identified.

\section{CONCLUSION}

This results showed that aerobic exercise had impact on re- duction of $\mathrm{BP}$ and $\mathrm{HR}$ of hypertensive patients. It is recommended to select an exercise according to the individual's preference, but if there is no preference, water-based exercise with the greatest drop in blood pressure can be more recommended. Although vigorous-intensity exercise was effective in lowering blood pressure, the risk to benefit of hypertensive patients should be considered when performing vigorous-intensity exercise. Frequency is recommended to perform 3 times per week or 2 times with vigorous-intensity. Also it is effective to keep the period longer than 8 weeks. In conclusion, aerobic exercise can be recommended in a variety of clinical settings to lower BP and HR in hypertensive patients.

\section{CONFLICTS OF INTEREST}

The authors declared no conflict of interest.

\section{ACKNOWLEDGEMENTS}

None.

\section{DATA SHARING STATEMENT}

Please contact the corresponding author for data availability.

\section{AUTHOR CONTRIBUTIONS}

Conceptualization or/and Methodology: Lee SH \& Chae YR.

Data curation or/and Analysis: Lee SH.

Funding acquisition: None.

Investigation: Lee SH \& Chae YR.

Project administration or/and Supervision: None.

Resources or/and Software: None.

Validation: Chae YR.

Visualization: Lee SH.

Writing original draft or/and Review \& editing: Lee SH \& Chae YR.

\section{REFERENCES}

1. Mancia G, Fagard R, Narkiewicz K, Redon J, Zanchetti A, Böhm M, et al. 2013 ESH/ESC guidelines for the management 
of arterial hypertension: The Task Force for the Management of Arterial Hypertension of the European Society of Hypertension (ESH) and of the European Society of Cardiology (ESC). European Heart Journal. 2013;34(28):2159-2219.

https://doi.org/10.1093/eurheartj/eht151

2. Korea Centers for Disease Control and Prevention. Korea health statistics 2018: Korea national health and nutrition examination survey (KNHANES VII-3) [Internet]. Sejong: Ministry of Health and Welfare; c2019 [cited 2020 Mar 1]. Available from: https://knhanes.cdc.go.kr/knhanes/sub04/ sub04_03.do.

3. The Korean Society of Hypertension. The guidelines of treatment of hypertension 2018 [Internet]. Seoul: The Korean Society of Hypertension; c2018 [cited 2019 Dec 1]. Available from: https://www.koreanhypertension.org/reference/guide?mode $=$ read\&idno $=4246$.

4. Turgut F, Yesil Y, Balogun RA, Abdel-Rahman EM. Hypertension in the elderly: Unique challenges and management. Clinics in Geriatric Medicine. 2013;29(3):593-609. https://doi.org/10.1016/j.cger.2013.05.002

5. Weber MA, Schiffrin EL, White WB, Mann S, Lindholm LH, Kenerson JG, et al. Clinical practice guidelines for the management of hypertension in the community: A statement by the American Society of Hypertension and the International Society of Hypertension. Journal of Clinical Hypertension. 2014;16(1):14-26. https://doi.org/10.1111/jch.12237

6. Ettehad D, Emdin CA, Kiran A, Anderson SG, Callender T, Emberson J, et al. Blood pressure lowering for prevention of cardiovascular disease and death: A systematic review and meta-analysis. Lancet. 2016;387(10022):957-967.

https://doi.org/10.1016/S0140-6736(15)01225-8

7. James PA, Oparil S, Carter BL, Cushman WC, Dennison-Himmelfarb C, Handler J, et al. 2014 evidence-based guideline for the management of high blood pressure in adults: Report from the panel members appointed to the Eighth Joint National Committee (JNC 8). Journal of the American Medical Association. 2014;311(5):507-520. https://doi.org/10.1001/jama.2013.284427

8. Riebe D, Ehrman JK, Liguori G, Magal M. ACSM's guidelines for exercise testing and prescription. 10th ed. Kim WS, Kang SJ, Kang HJ, Ko SK, Kim MH, Kim YS, et al., translator. Seoul: Hanmi Medical Publishing Co.; c2018. p. 117-132.

9. Mansia G, De Backer G, Dominiczak A, Cifkova R, Fagard R, Germano G, et al. 2007 ESH-ESC Guidelines for the management of arterial hypertension: The task force for the management of arterial hypertension of the European Society of Hypertension (ESH) and of the European Society of Cardiology (ESC). Blood Pressure. 2007;16(3):135-232. https://doi.org/10.1080/08037050701461084

10. Choi HJ, Lee TY, Oh HJ, Kim SH. The effect of pulse rate on the risk factors of cardiovascular disease in the adults. Journal of the Korean Academy of Family Medicine. 2007;28(6) :442450.

11. Palatini P. Role of elevated heart rate in the development of cardiovascular disease in hypertension. Hypertension. 2011;58(5):745-750. https://doi.org/10.1161/HYPERTENSIONAHA.111.173104

12. Börjesson M, Onerup A, Lundqvist S, Dahlöf B. Physical activity and exercise lower blood pressure in individuals with hypertension: Narrative review of 27 RCTs. British Journal of Sports Medicine. 2016;50(6):356-361. https://doi.org/10.1136/bjsports-2015-095786

13. Cornelissen VA, Smart NA. Exercise training for blood pressure: A systematic review and meta-analysis. Journal of the American Heart Association. 2013;2(1) :e004473.

https://doi.org/10.1161/JAHA.112.004473

14. Semlitsch T, Jeitler K, Hemkens LG, Horvath K, Nagele E, Schuermann C, et al. Increasing physical activity for the treatment of hypertension: A systematic review and meta-analysis. Sports Medicine. 2013;43(10):1009-1023. https://doi.org/10.1007/s40279-013-0065-6

15. Wen H, Wang L. Reducing effect of aerobic exercise on blood pressure of essential hypertensive patients: A meta-analysis. Medicine. 2017;96(11):e6150. https://doi.org/10.1097/MD.0000000000006150

16. Whelton SP, Chin A, Xin X, He J. Effect of aerobic exercise on blood pressure: A meta-analysis of randomized, controlled trials. Annals of Internal Medicine. 2002;136(7):493-503. https://doi.org/10.7326/0003-4819-136-7-20020402000006

17. Cao L, Li X, Yan P, Wang X, Li M, Li R, et al. The effectiveness of aerobic exercise for hypertensive population: A systematic review and meta-analysis. The Journal of Clinical Hypertension. 2019;21(7):868-876. https://doi.org/10.1111/jch.13583

18. Moher D, Liberati A, Tetzlaff J, Altman DG; PRISMA Group. Preferred reporting items for systematic reviews and meta-analyses: The PRISMA statement. International Journal of Surgery. 2010;8(5):336-341. https://doi.org/10.1016/j.ijsu.2010.02.007

19. Park DH, Kim CS, Kim KJ. Consideration about physical activity guideline and exercise intensity for adult. Exercise Science. $2015 ; 24(2): 99-107$. https://doi.org/10.15857/ksep.2015.24.2.99

20. Carlson DJ, Dieberg G, Hess NC, Millar PJ, Smart NA. Isometric exercise training for blood pressure management: A systematic review and meta-analysis. Mayo Clinic Proceedings. 2014;89(3):327-334. https://doi.org/10.1016/j.mayocp.2013.10.030

21. Higgins JPT, Savović J, Page MJ, Sterne JAC. Revised Co- 
chrane risk-of-bias tool for randomized trials (RoB 2) [Internet]. Bristol: The RoB2 Development Group; c2019 [cited 2019 Dec 1]. Available from: https://www.riskofbias.info/ welcome/rob-2-0-tool.

22. Higgins JPT, Green S. Cochrane handbook for systematic reviews of interventions version 5.1.0 [Internet]. London: The Cochrane Collaboration; c2011 [cited 2019 Dec 1]. Available from: https://handbook-5-1.cochrane.org/.

23. Son JU, Lee JH. The effect of the walking exercise on physiological index, physical fitness, self esteem, depression and life satisfaction in the institutionalized elderly women. Journal of Korean Academy of Community Health Nursing. 2006;17(1):5-16.

24. Halliwill JR, Buck TM, Lacewell AN, Romero SA. Postexercise hypotension and sustained postexercise vasodilatation: What happens after we exercise? Experimental Physiology. 2013;98(1):7-18. https://doi.org/10.1113/expphysiol.2011.058065

25. Laughlin MH, Davis MJ, Secher NH, van Lieshout JJ, Arce-Esquivel AA, Simmons GH, et al. Peripheral circulation. Comprehensive Physiology. 2012;2(1):321-447. https://doi.org/10.1002/cphy.c100048

26. Mun CI, Yoo JI, Kim DJ. The effects of preference mode of exercise on participants' psychological and physiological responses. Korean Journal of Sport Science. 2008;19(1) :124135. https://doi.org/10.24985/kjss.2008.19.1.124

27. Park JY, Min HJ, Kim NJ. Effects of 26 weeks senior body rhythm exercise program of physical fitness and serum lipid and bone mineral density in post-menopausal elderly women. The Korean Journal of Dance. 2008;57(1):85-100.

28. Kwon MG, Kim YJ. Study on the application of exercise type in exercise intensity setting. The Korean Journal of Sport. 2017;15(2):947-955

29. Oda E, Kawai R. Significance of heart rate in the prevalence of metabolic syndrome and its related risk factors in Japanese. Circulation Journal. 2009;73(8):1431-1436. https://doi.org/10.1253/circj.cj-08-1142

30. Kang SJ, Kim EH, Ko KJ. Effects of aerobic exercise on the resting heart rate, physical fitness, and arterial stiffness of female patients with metabolic syndrome. Journal of Physical Therapy Science. 2016;28(6):1764-1768. https://doi.org/10.1589/jpts.28.1764 
Appendix 1. Studies Included in Systematic Review and Meta-Analysis (37 studies)

A1. Knoepfli-Lenzin C, Sennhauser C, Toigo M, Boutellier U, Bangsbo J, Krustrup P, et al. Effects of a 12-week intervention period with football and running for habitually active men with mild hypertension. Scandinavian Journal of Medicine and Science in Sports. 2010;20(suppl.1):72-79. https://doi.org/10.1111/j.1600-0838.2009.01089.x

A2. Motlagh Z, Hidarnia A, Kaveh MH, Kojuri J. Effect of theory-based training intervention on physical activity and blood pressure in hypertensive patients: A randomized control trial. Iran Red Crescent Medical Journal. 2017;19(7) :e55610.

https://doi.org/10.5812/ircmj.55610

A3. Hong SK, Lee DG, Lee GC. Effect of aerobic exercise on blood pressure and arterial compliance in patients with essential hypertension. Journal of Exercise Physiology Online. 2018;21(5):9-18.

A4. Mohr M, Nordsborg NB, Lindenskov A, Steinholm H, Nielsen HP, Mortensen H, et al.

High-intensity intermittent swimming improves cardiovascular health status for women with mild hypertension. BioMed Research International. 2014;2014:728289. https://doi.org/10.1155/2014/728289

A5. de Barros Cruz LG, Bocchi EA, Grassi G, Guimaraes GV. Neurohumoral and endothelial responses to heated water-based exercise in resistant hypertensive patients. Circulation Journal. 2017;81(3):339-345. https://doi.org/10.1253/circj.CJ-16-0870

A6. Arca EA, Martinelli B, Martin LC, Waisberg CB, Franco RJ. Aquatic exercise is as effective as dry land training to blood pressure reduction in postmenopausal hypertensive women. Physiotherapy Research International. 2014;19(2):93-98.

https://doi.org/10.1002/pri.1565

A7. Izadi MR, Afousi AG, Fard MA, Bigi MAB. High-intensity interval training lowers blood pressure and improves apelin and NOx plasma levels in older treated hypertensive individuals. Journal of Physiology and Biochemistry. 2018;74(1):47-55.

https://doi.org/10.1007/s13105-017-0602-0

A8. Maruf FA, Akinpelu AO, Salako BL. A randomized controlled trial of the effects of aerobic dance training on blood lipids among individuals with hypertension on a thiazide. High Blood Pressure \& Cardiovascular Prevention. 2014;21(4):275-283.

https://doi.org/10.1007/s40292-014-0063-2

A9. Kaholokula JK. Look M. Mabellos T, Zhang G, Silva M, Yoshimura S, et al. Cultural dance program improves hypertension management for native Hawaiians and pacific Islanders: A pilot randomized trial. Journal of Racial and Ethnic Health disparities. 2017;4(1):35-46. https://doi.org/10.1007/s40615-015-0198-4

A10. Wong A, Figueroa A, Son WM, Chernykh O, Park SY. The effects of stair climbing on arterial stiffness, blood pressure, and leg strength in postmenopausal women with stage 2 hypertension. Menopause. 2018;25(7):731-737.

https://doi.org/10.1097/GME.0000000000001072

A11. Wong A, Kwak YS, Scott SD, Pekas EJ, Son WM, Kim JS, et al. The effects of swimming training on arterial function, muscular strength, and cardiorespiratory capacity in postmenopausal women with stage 2 hypertension. Menopause. 2018;26(6):653-658.

https://doi.org/10.1097/GME.0000000000001288

A12. Krustrup P, Randers MB, Andersen LJ, Jackman SR, Bangsbo J, Hansen PR. Soccer improves fitness and attenuates cardiovascular risk factors in hypertensive men. Medicine \& Science in Sports \& Exercise. 2013;45(3):553-561.

https://doi.org/10.1249/MSS.0b013e3182777051

A13. Kim KH. The Effects of Regular Senior Aerobic Exercise on Resting Bloods Pressure and Cardiovascular Responses of in Older Women with Hypertension. Journal of Korean Physical Education Association for Girls and Women. 2013;27(1):179-192.

A14. Kim JH. The Effect of dance program on the serum lipids and blood pressure and leptin of obese elderly women with hypertension. Official Journal of the Korean Society of Dance Science. 2014;31(3):83-93.

A15. Duncan JJ, Farr JE, Upton SJ, Hagan RD, Oglesby ME, Blair SN. The effects of aerobic exercise on plasma catecholamines and blood pressure in patients with mild essential hypertension. JAMA. 1985;254(18):2609-2613.

https://doi.org/10.1001/jama.1985.03360180113036

A16. Urata H, Tanabe Y, Kiyonaga A, Ikeda M, Tanaka H, Shindo M, et al. Antihypertensive and volume-depleting effects of mild exercise on essential hypertension.

Hypertension. 1987;9(3):245-252. https://doi.org/10.1161/01.hyp.9.3.245

A17. Hagberg JM, Montain SJ, Martin WH, Eshani AA. Effect of exercise training in 60- to 69-year-old persons with essential hypertension. The American Journal cardiology. 1989;64(5):348-353. https://doi.org/10.1016/0002-9149(89)90533-x

A18. Kokkinos PF, Narayan P, Colleran JA, Pittaras A, Notargiacomo A, Reda D, et al. Effects of regular exercise on blood pressure and left ventricular hypertrophy in African-American men with severe hypertension. The New England Journal of Medicine. 
1995;333(22):1462-1467. https://doi.org/10.1056/NEJM199511303332204

A19. Tanaka H, Bassett DR, Howley ET, Thompson DL, Ashraf M, Lawson FL, Swimming training lowers the resting blood pressure in individuals with hypertension. Journal of Hypertension. 1997;15(6):651-657.

https://doi.org/10.1097/00004872-199715060-00012

A20. Cooper AR, McKenna, Riddoch CJ. What is the magnitude of blood pressure response to a programme of moderate intensity exercise? randomized controlled trial among sedentary adults with unmedicated hypertension. British Journal of General Practice. 2000;50(461):958-962.

A21. Staffileno BA, Braun LT, Rosenson RS. The accumulative effects of physical activity in hypertensive post-menopausal women. Journal of Cardiovascular Risk. 2000;8(5):283-290. https://doi.org/10.1177/174182670100800507

A22. Tsai JC, Yang HY, Wang WH, Hsieh MH, Chen PT, Kao CC, et al. The beneficial effect of regular endurance exercise training on blood pressure and quality of life in patients with hypertension. Clinical and Experimental Hypertension. 2004;26(3):255-265. https:// doi.org/10.1081/CEH-120030234

A23. Sohn AJ, Hasnain M, Sinacore JM. Impact of exercise (walking) on blood pressure levels in African American adults with newly diagnosed hypertension. Ethnicity and Disease. 2007;17(3):503-507.

A24. Westhoff TH, Franke N, Schmidt S, Vallbracht-Israng K, Meissner R, Yildirim H, et al. Too old to benefit from sports? The cardiovascular effects of exercise training in elderly subjects treated for isolated systolic hypertension. Kidney Blood Pressure Research. 2007;30(4):240-247. https://doi.org/10.1159/000104093

A25. Westhoff TH, Schmidt S, Gross V, Joppke M, zidek W, van der Giet M, et al. The cardiovascular effects of upper-limb aerobic exercise in hypertensive patients. Journal of Hypertension. 2008;26(7):1336-1342. https://doi.org/10.1097/HJH.0b013e3282ffac13

A26. Guimarães GV, Ciolac EG, Carvalho VO, D’Avila VM, Botolotto LA, Bocchi EA. Effects of continuous vs interval exercise training on blood pressure and arterial stiffness in treated hypertension. Hypertension Research. 2010;33(6):627-632.

A27. Andersen LJ, Randers MB, Westh K, Martone D, Hansen PR, Junge A, et al. Football as a treatment for hypertension in untrained 30-55-year-old men: a prospective randomized study. Scandinavian Journal of Medicine and Science in Sports. 2010;20(S1):98-102. https://doi.org/10.1111/j.1600-0838.2010.01109.x

A28. Aminuddin A, Zakaria Z, Nordin NAMM, Karim AAH, Maskon O, Pei TS et al. Effect of graded aerobic exercise training on blood pressure changes in women with elevated blood pressure. International Medical Journal. 2011;18(3):207-211.

A29. Molmen-Hansen HE, Stolen T, Tjonna AE, Aamot IL, Ekeberg IS, Tyldum GA, et al. Aerobic interval training reduces blood pressure and improves myocardial function in hypertensive patients. European Journal of Preventive Cardiology. 2012;19(2):151-160. https://doi.org/10.1177/1741826711400512

A30. Kim JH. The Effect of dance program on the serum lipids and blood pressure and leptin of obese elderly women with hypertension. Official Journal of the Korean Society of Dance Science. 2014;31(3):83-93.

A31. Dimeo F, Pagonas N, Seibert F, Arndt R, Zidek W, Westhoff TH. Aerobic exercise reduces blood pressure in resistant hypertension. Hypertension. 2012;60(3) :653-658. https://doi.org/10.1161/HYPERTENSIONAHA.112.197780

A32. Kwon OS, Kim JH, Lee SH. Effect of aquarobic training according to body composition, blood pressure on inflammatory markers in middle age hypertensive women. Korean Journal of Sport Science. 2013;22(5):1243-1256.

A33. Guimaraes GV, de Barros Cruz LG, Fernandes-Silva MM, Dorea EL, Bocchi EA. Heated water-based exercise training reduces 24-hour ambulatory blood pressure levels in resistant hypertensive patients: a randomized controlled trial (HEx trial). International Journal of Cardiology. 2014;172(2):434-441. https://doi.org/10.1016/j.ijcard.2014.01.100

A34. Tsuda K, Yoshikawa A, Kimura K, Nishio I. Effects of mild aerobic physical exercise on membrane fluidity of erythrocytes in essential hypertension. Clinical and Experimental Pharmacology and Physiology. 2003;30(5, 6):382-386.

https://doi.org/10.1046/j.1440-1681.2003.03846.x|

A35. Sikiru L, Okoye GC. Therapeutic effect of continuous exercise training program on serum creatinine concentration in men with hypertension: A randomized controlled trial. Ghana Medical Journal. 2014;48(3);135-142. https://doi.org/10.4314/gmj.v48i3.3

A36. Lima LG, Bonardi JTM, Campos GO, Bertani RF, Scher LML, Moriguti JC, et al. Combined aerobic and resistance training: Are there additional benefits for older hypertensive adults?. Clinical Science. 2017;72(6):363-369. https://doi.org/10.6061/clinics/2017(06)06

A37. He L, Wei WR, Can Z. Effects of 12-week brisk walking training on exercise blood pressure in elderly patients with essential hypertension: A pilot study. Clinical and Experimental Hypertension. 2018;40(7):673-679.

https://doi.org/10.1080/10641963.2018.1425416 
Appendix 2. Assessment result of risk of bias in included studies

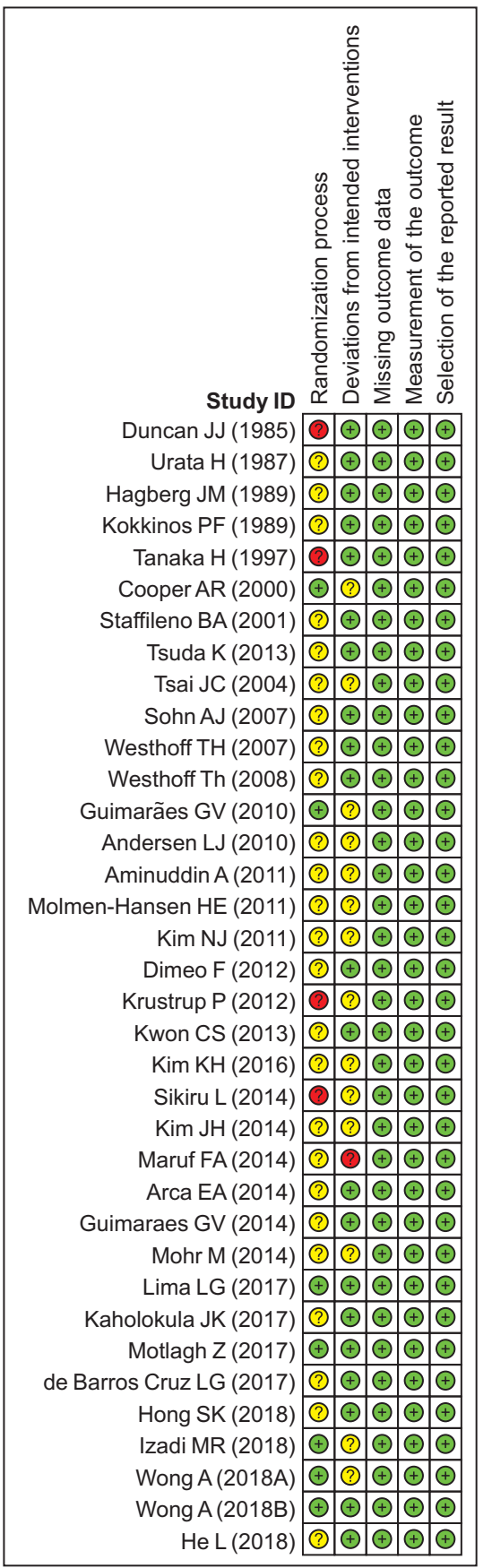

(†) Low risk

(2) Some concerns High risk
Appendix 3. Funnel plot of the effects of SBP, DBP and HR

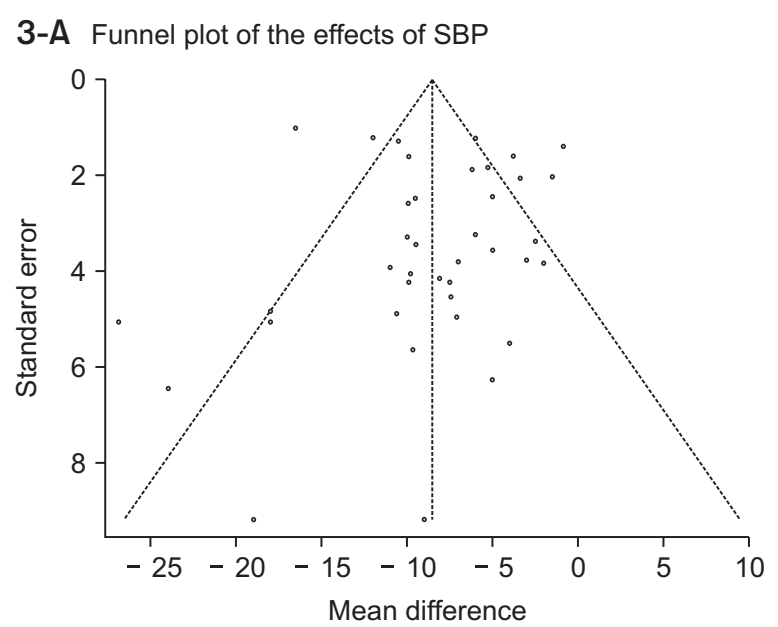

3-B Funnel plot of the effects of DBP

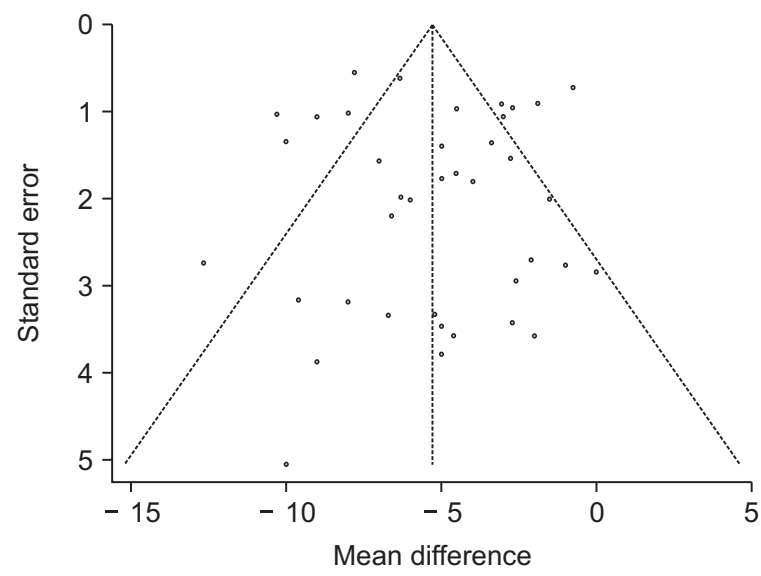

3-C Funnel plot of the effects of HR

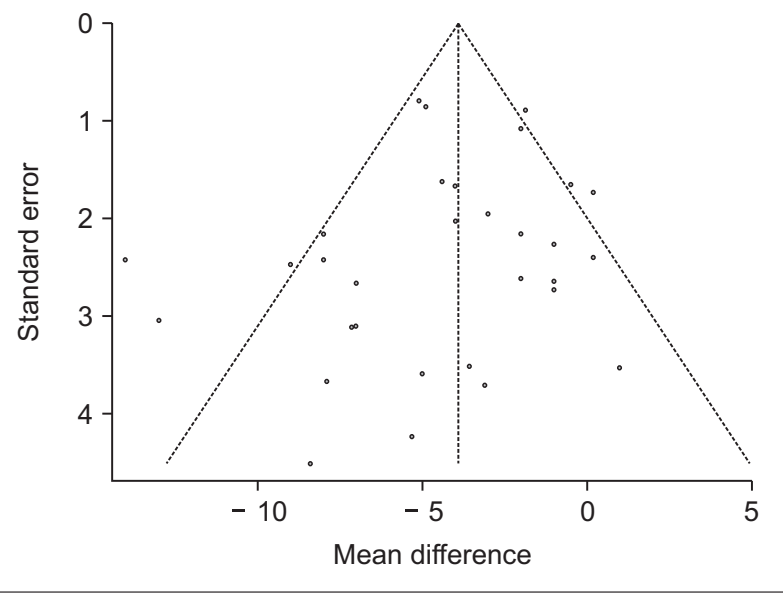

$\mathrm{DBP}=$ Diastolic blood pressure; $\mathrm{HR}=$ Heart rate; $\mathrm{SBP}=$ Systolic blood pressure. 